\title{
Fractionated palliative thoracic radiotherapy in non-small cell lung cancer - futile or worth-while?
}

\author{
Malene Støchkel Frank ${ }^{1 \dagger}$, Dorte Schou Nørøxe ${ }^{1 * \dagger}\left(\mathbb{D}\right.$, Lotte Nygård ${ }^{1,2}$ and Gitte Fredberg Persson ${ }^{1}$
}

\begin{abstract}
Background: Palliative thoracic radiotherapy (PTR) can relieve symptoms originating from intra-thoracic disease. The optimal timing and fractionation of PTR is unknown. Time to effect is 2 months. The primary aim of this retrospective study was to investigate survival after PTR, hypothesizing that a significant number of patients received futile fractionated PTR. The secondary aim was to find prognostic factors to guide treatment decisions.

Methods: Patients with non-small-cell lung cancer (NSCLC) planned for PTR in the period of 2010-2011 at the University Hospital of Copenhagen were included. We noted pathology, tumor, node and metastasis (TNM) classification of malignant tumors, stage, indication, start date, schedule for PTR, completed $y / n$, performance status (PS) and time of death. Analyses were performed as an intention-to-treat using Cox regression, Fishers exact test and Kaplan Meier.

Results: A total of 159 patients were included. Median overall survival (OS) was 4.2 months. Sixteen patients (10\%) did either not begin or finish PTR. Of these, eight (5\%) died prior to or during PTR. Of the 151 patients receiving PTR, sixteen patients (11\%) died within 14 days, thirty-three (22\%) within 30 days and fifty (33\%) within 2 months. PS 0-1 and squamous cell carcinoma were correlated with a better survival.

Conclusions: Our study show that a significant number of patients who received PTR died before they could achieve optimal effect of the treatment. PS and histology were significant prognostic factors favoring PS 0-1 and squamous cell carcinoma. Based on our study, we suggest that patients with PS 0-1 should be considered for fractionated PTR whereas patients with PS $\geq 2$ should be considered for high dose single fraction only or supportive palliative care.
\end{abstract}

Keywords: Non-small-cell lung cancer, NSCLC, Radiotherapy, Palliative, Thoracic, Overall survival, Performance status, Ps

\section{Background}

Non-small-cell lung cancer (NSCLC) is the leading cause of cancer related death [1]. When diagnosed, more than $50 \%$ of the patients have distant metastases. $40 \%$ of the patients have signs or symptoms originating from the thorax with dyspnoea, cough, haemoptysis, recurrent pneumonia or chest pain [2].

Median overall survival (OS) (all stages) without treatment or with platinum-based chemotherapy is 7 months and 8-10 months, respectively [3]. Considering the poor prognostic setting and the clinical symptoms which often

\footnotetext{
* Correspondence: anne.dorte.schou.noeroexe@regionh.dk

${ }^{\dagger}$ Equal contributors

'Department of Oncology, Finsen Center, Rigshospitalet, Blegdamsvej 9, 2100

Copenhagen, Denmark

Full list of author information is available at the end of the article
}

affect quality of life (QoL), it is important to focus on a meaningful palliative strategy.

Palliative thoracic radiotherapy (PTR) can relieve symptoms originating from intra-thoracic malignancy and improves QoL in approximately one third of all patients [4].

An optimal radiotherapy regimen will palliate symptoms with minimal toxicity and consider the time investment for the patient. A recent systematic review [5] found no consistent evidence that longer, more fractionated regimens gave better or more durable palliation. Furthermore, there was no significant survival advantage associated with longer regimens with higher biological doses.

The American Society for Radiation Oncology's (ASTRO) evidence-based clinical practice guidelines suggest that 
patients with good performance status (PS) may benefit from a higher-dose/fractionated regimen (30Gy/10F equivalent or greater) in terms of a modest survival benefit. Various shorter fractionated schedules (e.g. 20Gy/5F, $17 \mathrm{~Gy} / 2 \mathrm{~F}$ and $10 \mathrm{~Gy} / 1 \mathrm{~F}$ ) provide symptomatic relief and can be used for patients requesting shorter total treatment courses or who have a poor PS [6]. Another important factor when choosing palliative strategy is time to effect. In a randomized study comparing $30 \mathrm{~Gy} / 10 \mathrm{~F}$ to $16 \mathrm{~Gy} / 2 \mathrm{~F}$, the median time to effect was 7 weeks and 5 weeks respectively [7]. An individualized strategy based upon PS, symptom severity, the choice of the patient and an estimation of life expectancy has proven important when choosing a fractionated schedule and whether to give PTR or not [8-10]. Supportive care alone should be considered. Walasek et al. [11] showed that patients in a poor PS (3-4) and stage IIIB/IV experienced equally symptom palliation and survival with radiotherapy compared to supportive care alone. PS is considered the predominant prognostic factor and a significant predictor for futile radiotherapy at the end of life $[8,9,12-20]$.

We hypothesize that a significant part of fractionated PTR to patients with NSCLC is futile as patients do not live long enough to achieve the complete effect of the treatment. In this article, we will use the word futile as being ineffective or insufficient and will argue that PTR administered within the last 30 days of life is futile.

In this retrospective study, we investigated OS after PTR and aimed to find prognostic factors to guide treatment decisions.

\section{Methods}

Patients planned for PTR between the 1st of January 2010 and 31st of December 2011 at the University Hospital of Copenhagen (Rigshospitalet) were identified in our ARIA database (Varian medical systems). The standard palliative radiotherapy schedules were $30 \mathrm{~Gy} / 10 \mathrm{~F}, 25 \mathrm{~Gy} / 5 \mathrm{~F}$, $15 \mathrm{~Gy} / 3 \mathrm{~F}$ and $10 \mathrm{~Gy} / 1 \mathrm{~F}$. Only patients with pathologically confirmed NSCLC were included for further analysis. Date of birth, date of diagnosis, pathology including epidermal growth factor receptor (EGFR)-status (if available), tumor, node and metastasis (TNM) classification of solid, malignant tumors (7th edition), stage, treatment schedule, PS at time of subscription of PTR, indication for PTR and time of death was extracted from the electronic patient chart. If missing, PS was estimated based on chart notes. Fractionated schedule, date of radiotherapy (start/end) and number of fractions received were retrieved through the ARIA planning programme. Prescription date was set 2 weeks prior to PTR. In cases where patients died prior to or did not begin PTR, the actual prescription date was noted. Data lock was 5th of April 2016. PTR was considered futile if patients died within 30 days of treatment start.
Table 1 Patient-characteristics $(n=159)$

\begin{tabular}{ll}
\hline Patient Characteristics & no (\%) \\
\hline Age at PTR start (years) & \\
$<70$ years & $78(49)$ \\
$\geq 70$ years & $81(51)$ \\
Histology & \\
Adenocarcinoma & $77(48)$ \\
Squamous cell carcinoma & $69(43)$ \\
Mixed adeno-squamous cell carcinoma & $11(7)$ \\
NA & $2(1)$ \\
Stage & \\
I & $5(3)$ \\
II & $7(4)$ \\
III & $53(33)$ \\
IV & $94(59)$
\end{tabular}

WHO Performance Status

\begin{tabular}{|c|c|}
\hline 0 & $14(9)$ \\
\hline 1 & $62(39)$ \\
\hline 2 & $47(30)$ \\
\hline 3 & $33(21)$ \\
\hline 4 & $3(2)$ \\
\hline \multicolumn{2}{|l|}{ ndication for PTR } \\
\hline Dyspnea & $58(30)$ \\
\hline Pain & $47(24)$ \\
\hline Hemoptysis & $22(11)$ \\
\hline Cough & $18(9)$ \\
\hline Vena cava superior syndrome & $16(8)$ \\
\hline Dysphagia & $4(2)$ \\
\hline Other & $30(15)$ \\
\hline \multicolumn{2}{|l|}{ DTR Schedules } \\
\hline 30Gy/10F & $101(64)$ \\
\hline $25 \mathrm{~Gy} / 5 \mathrm{~F}$ & $50(31)$ \\
\hline 15Gy/3F & $7(4)$ \\
\hline 10Gy/1F & $1(1)$ \\
\hline \multicolumn{2}{|l|}{ Primary Treatment after diagnosis } \\
\hline Chemotherapy & $74(47)$ \\
\hline Radiotherapy & $58(36)$ \\
\hline Surgery & $12(8)$ \\
\hline Other & $8(5)$ \\
\hline Not treated & $3(2)$ \\
\hline NA & $4(3)$ \\
\hline \multicolumn{2}{|c|}{ Number of Chemotherapy Regimens } \\
\hline 0 & $59(37)$ \\
\hline 1 & $35(22)$ \\
\hline 2 & $26(16)$ \\
\hline 3 & $16(10)$ \\
\hline$>3$ & $18(11)$ \\
\hline NA & $5(3)$ \\
\hline
\end{tabular}




\section{Statistical analysis}

Statistical analyses were based on intention to treat (from prescription time to death). Kaplan-Meier was used for survival analysis and cox regression was performed for the multivariate analyses. We investigated PS, pathology, stage, fractionated schedules (30Gy/10F versus $25 \mathrm{~Gy} / 5 \mathrm{~F}$ ) and age below median age of the population (70 years). A two-sided $p$-value below 0.05 was considered statistical significant.

\section{Results}

A total of 216 patients were referred for PTR between the 1st of January 2010 and 31st of December 2011. Fifty-two patients had a diagnosis other than NSCLC. Five patients without follow-up were excluded. A total of 159 patients were included for further statistical analysis. Primary treatment was first treatment given to the patient after diagnosis.

Patient-characteristics are shown in Table 1. We found that PS was missing in approximately one third of the patients. The group was heavily pretreated before PTR with 18 patients (11\%) received $>3$ regimes of chemotherapy. We did not note if a patient received chemotherapy after PTR but PTR was in almost all cases the last treatment that the patient received. This can be seen in the median OS of 4.2 months from time of prescription of PTR to death.
See Fig. 1. A relative large group of patients had stage I-II disease and could potentially be candidates for curative radiotherapy together with a subset of patients with stage III disease. This treatment was not given due to comorbidity and/or PS not suitable for curative radiotherapy.

Sixteen patients (10\%) did not complete PTR: Eight (5\%) died prior to or during PTR, four patients were in too poor a condition, two patients withdrew their consent, one had too large a target and for one patient the reason was not stated. Of the 151 patients receiving PTR, sixteen patients (11\%) died within 14 days. Thirty-three patients (22\%) died within 30 days and fifty patients (33\%) died within 2 months of treatment.

Dyspnea and pain were the most frequent stated indications for PTR. Each patient could be noted for more than one indication. The most frequent fractionated schedule was $30 \mathrm{~Gy} / 10 \mathrm{~F}(64 \%)$.

The median time from prescription to death of all patients was 4.2 months (0-73). Two patients were still alive at data lock (Fig. 1).

Overall, the most common fractionated schedule was $30 \mathrm{~Gy} / 10 \mathrm{~F}$ and thereafter $25 \mathrm{~Gy} / 5 \mathrm{~F}$. Most patients dying within 60 days of treatment received 25Gy/5F followed by $30 \mathrm{~Gy} / 10 \mathrm{~F}$ and only three patients (3\%) received a shorter fractionation. The difference between the regimens

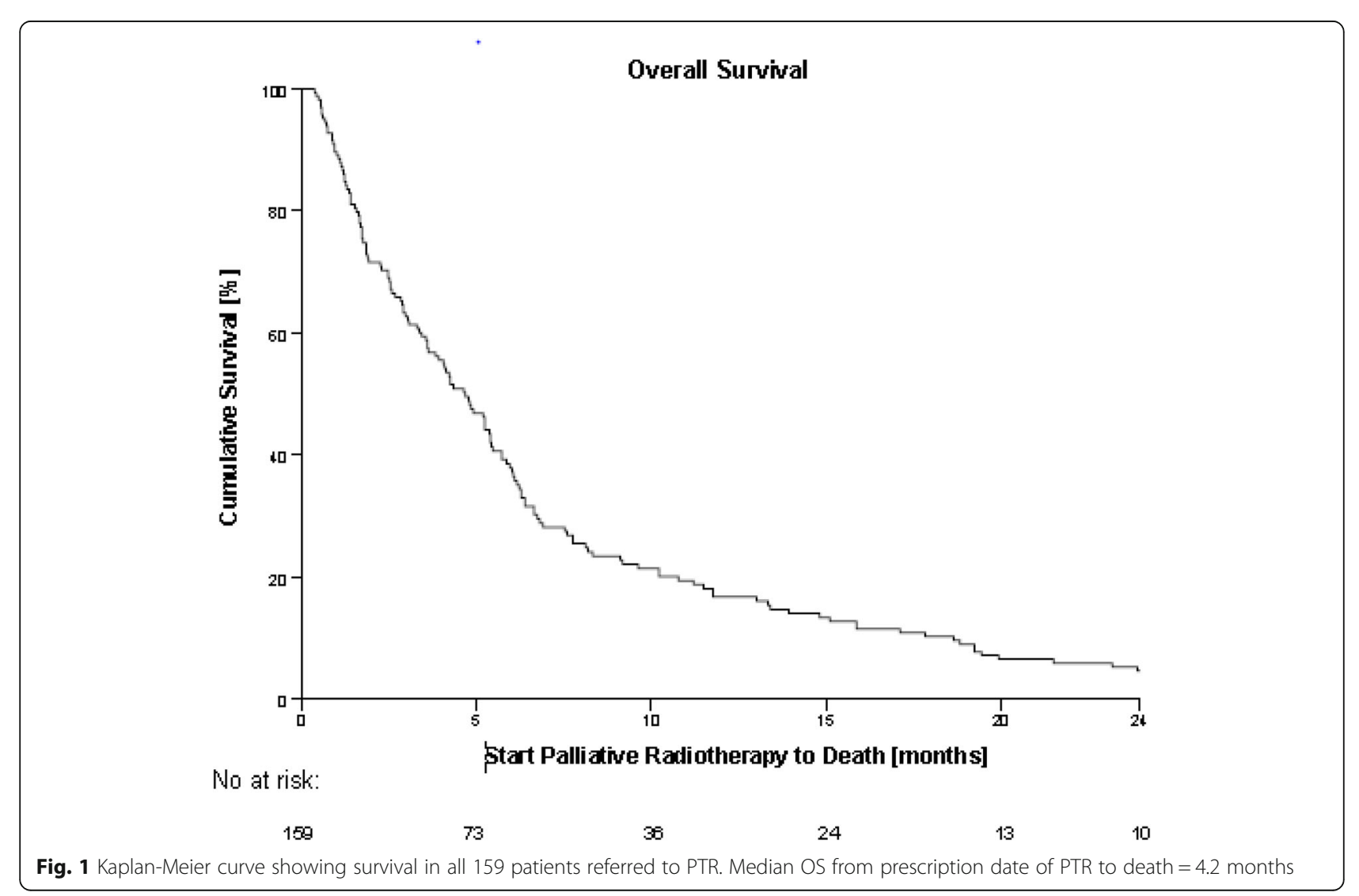


was based on PS as our guidelines suggested a shorter fractionation to patients in PS $>2$. Haemoptysis was present in $11 \%$ of the patient-cases but only $4 \%$ received $15 \mathrm{~Gy} / 3 \mathrm{~F}$, which was the recommended fractionated schedule for haemoptysis. As EGFR-status was not routinely performed at our institution in 2010-2011 but only a selected group of patients, e.g. young women and/or never smokers, we only obtained EGFR-mutational status in 13 patients of which one had mutation in exon 19. These numbers were too small to analyse.

Only PS and histology were statistical significant in cox univariate analyses and were included for further analysis. Cox regression analysis for stage, fractionated schedules and age below the median can be found in (Additional file 2: Figure S2 and Additional file 3: Figure S3).

PS 0 and 1 were grouped in one category as the groups would otherwise be too small for further analysis. Statistical analysis showed a significant difference in OS between PS 0-1, 2 and 3-4 in favor of PS 0-1 (Fig. 2). There was no difference in OS between PS 2 and 3-4. We found a significant difference between OS and histology favoring mixed adeno-squamous-cell carcinoma and squamous-cell carcinoma (SCC) over adenocarcinoma (AC) (Fig. 3). Due to a small number of patients in the category mixed adeno-squamous-cell carcinoma, these patients were excluded for further analysis in the multivariate cox regression analysis (Additional file 1: Figure S1). Stage, age and fractionation schedule had no significant impact on OS (Additional file 2: Figure S2 and Additional file 3: Figure S3).

\section{Discussion}

Our results support our hypothesis that a significant number of patients in our department received futile or insufficient/ineffective fractionated PTR. We estimated that they did not live long enough to achieve the optimal

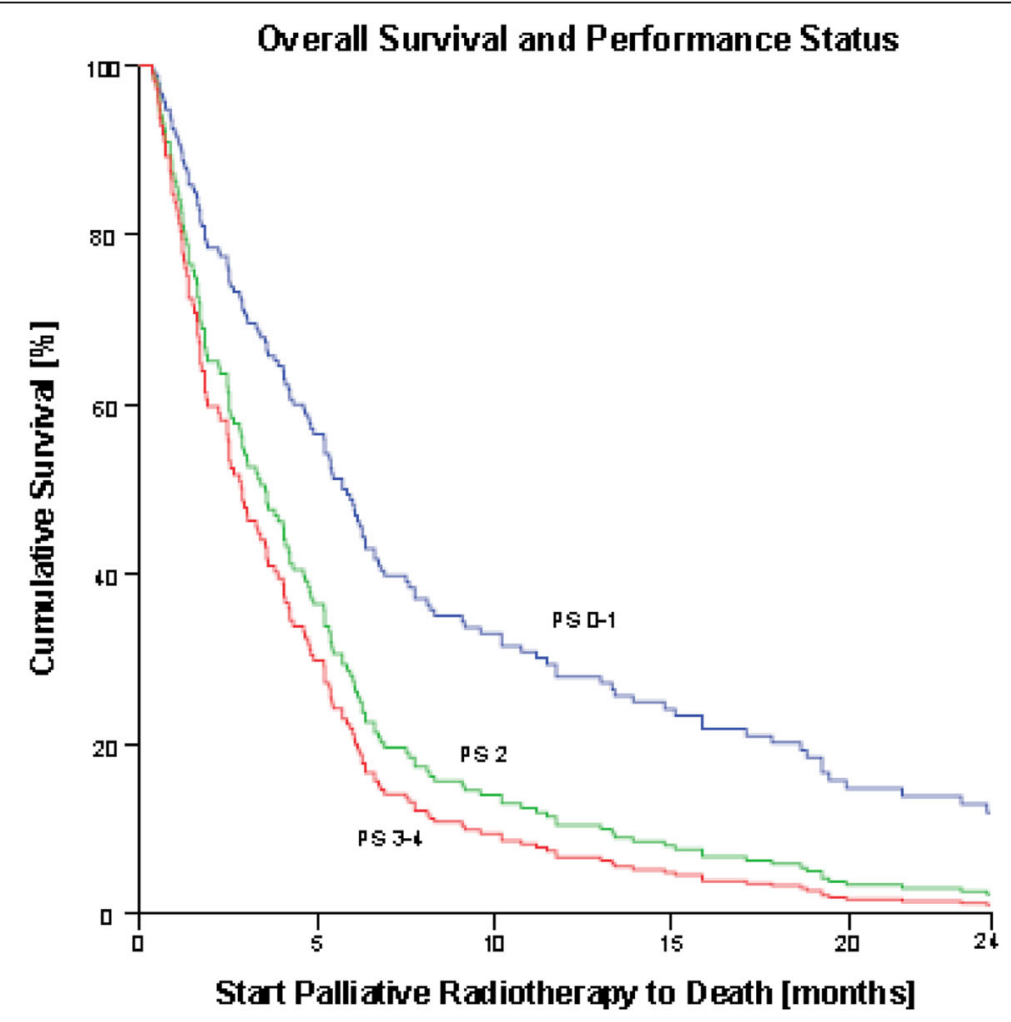

No at risk

$\begin{array}{lllllll}\operatorname{PS} \mathrm{C}-1 & 75 & 41 & 23 & 16 & 10 & 2 \\ \operatorname{PS} 2 & 47 & 15 & 6 & 4 & 1 & 0 \\ \operatorname{PS} 3-4 & 35 & 8 & 5 & 3 & 2 & 1\end{array}$

Fig. 2 Cox regression analysis showing correlation between OS and PS from prescription of PTR to death. There was a significant difference in OS and PS 0-1 and 2-4. PS 2: hazard ratio (HR) $=1.77,(95 \% \mathrm{Cl}: 1.22-2.57), p=0.003$. PS 3-4: HR=2.12 (95\% Cl: 1.42 to 3.17), $p<0.000$. There was no statistical difference in OS and PS 2 and 3-4 


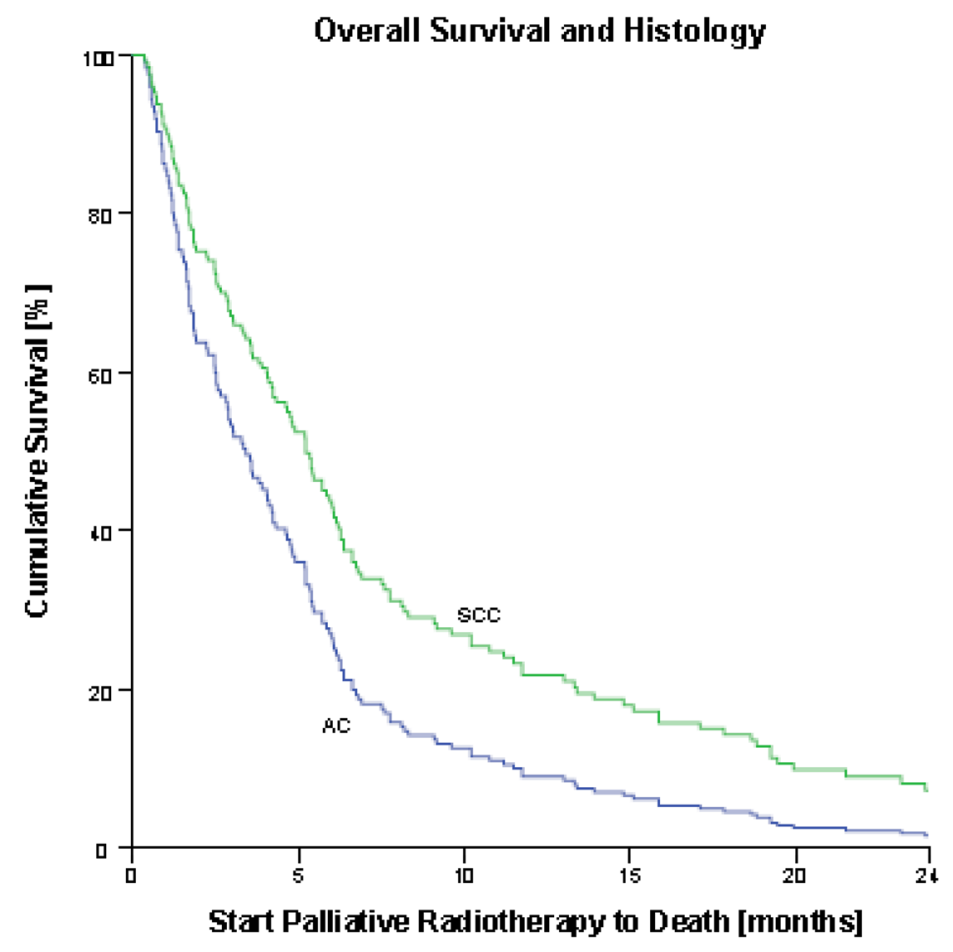

Wo at risk

$\begin{array}{lllllll}90 & 69 & 38 & 18 & 13 & 5 & 2 \\ \mathrm{AC} & 77 & 17 & 9 & 5 & 3 & 2\end{array}$

Fig. 3 Cox regression analysis showing correlation between OS and histology from prescription of PTR to death. There was a significant difference in OS and histology, favoring squamous-cell carcinoma (SCC) over adenocarcinoma (AC). SCC had a HR=0.63 (95\% Cl: 0.46 to $0.89), p=0.007$

effect of the treatment since $22 \%$ died within 30 days of treatment. Furthermore, 5\% died before or during treatment. Our data support that PS is the most important prognostic factor. We found a significant difference in OS between PS 0-1 and 2-4 in favor of patients in PS 0-1, but no significant difference between PS 2 and PS 3-4.

A relative small amount of studies have investigated palliative radiotherapy in the last 14, 30 and 60 days of life [15, 21-24]. The heterogeneity among these studies makes a direct comparison with our data difficult. Van Oorschot et al. [24] found that $12.7 \%$ of the patients with NSCLC receiving PTR, started treatment less than 30 days before death. This is consistent with our data where $16 \%$ started PTR in the last 30 days before death.

We found a median OS of 4.2 months after PTR. This is lower than compared to 4-12 months in other studies $[14,25-29]$. This can partly be explained by that $92 \%$ in our patient population had stage III/IV disease and a median PS of 2. Almost half of the patients received chemotherapy prior to PTR.

Sundstrøm et al. [30] analyzed data from 301 patients with NSCLC stadium III receiving 3 different fractionated schedules (17Gy/2F, 42Gy/15F or $50 \mathrm{~Gy} / 25 \mathrm{~F}$ ) and found that appetite loss, use of steroids and role function loss, but not Karnofsky score, were statistically significant predictors of OS. Gripp et al. [15] looked specifically at patients (all diagnosis) dying within 30 days of palliative radiotherapy to identify prognostic factors and found that Karnofsky score $<50 \%$ (WHO PS 3-4), brain metastases and dyspnoea at rest to be independently associated with an unfavourable prognosis. Van Oorshot et al. [24] investigated prognostic factors among 120 patients with NSCLC receiving different fractionated regimens and found that non-metastatic disease and PS, but not comorbidity, were significant predictors for survival. Rades et al. recently found a significant correlation between $\mathrm{N}$ and $\mathrm{M}$ stage and survival in palliative radiotherapy for locally advanced lung cancer. Karnofsky score $>70$ was borderline significant for survival. This was validated in a larger retrospective study [31, 32].

We also found a significant difference in OS and histology showing a better outcome for patients with SCC compared to AC. An explanation could be that AC more often originates in the periphery which gives symptoms later than a central location and is therefore diagnosed in a more advanced stage. 
Few studies have looked specifically at histology as a prognostic factor in palliative radiotherapy. In these, no statistical significance has been found [15, 21, 24].

Despite this heterogeneity, none of the above-mentioned studies revealed age as a prognostic factor, as supported by our findings. This raises the question that elderly patients maybe should not be treated different than the younger, as stated by Turner et al. [33] who showed no significant differences in response nor toxicity regarding PTR between two groups of patients $>75$ or $<65$ years, respectively.

A differentiation between symptoms and effect of PTR is useful. The rate of palliation is $60-80 \%$ for chest pain and haemoptysis while breathlessness and cough are controlled at a somewhat lower rate of $50-70 \%$. General symptoms as fatigue, anorexia and depression are only affected in a minority of treated patients. PTR rarely helps dysphagia and hoarseness [14, 17, 18, 26-29]. At our institution we found that dyspnea and pain were the most frequent indications for PTR. The third most frequent indication was the category "other" which included patients with no clear indication for PTR. But it also included patients with comorbidity that excluded chemotherapy. This is an interesting aspect as two different studies [34, 35] showed that radiotherapy given to asymptomatic patients does not prevent development of disease-related symptoms and has no beneficial impact on QoL or survival. Thus, delaying radiotherapy seems to be acceptable in asymptomatic patients with locally advanced NSCLC.

American Society of Clinical Oncology (ASCO) has published a guide to manage chemotherapeutic agents in terminally ill patients. Chemotherapy provided within the last 14 days of life as well as treatment courses initiated within 30 days of death is considered as overutilization of chemotherapy [36, 37]. No similar comprehensive guidelines exist for radiotherapy. In approximately three-quarters of lung cancer cases, radiotherapy is indicated and most applied radiotherapy is palliative [38]. Since shorter fractionated treatment or high-dose single fraction PTR provides faster symptom relief and causes fewer side effects, $[6,7]$ this strategy could provide a meaningful alternative compared to a longer fractionated treatment for patients with $P S \geq 2$ and hence not be futile or ineffective/ insufficient. The number of patients receiving single fraction PTR in this study were too few to conclude this.

\section{Conclusion}

Our study supports the need for guidelines to avoid futile or ineffective/insufficient fractionated PTR at the end of life. The retrospective study design with the moderate number of patients is a limitation to our study. A larger scale prospective study is needed to validate the findings. Following the patients after completion of PTR could supply us with the lacking knowledge of time to effect on symptoms and duration of palliation. An incorporation of QoL by questionnaires should be mandatory in a clinical trial. Also the role of pathological subtypes needs to be validated.

In our study we found that $22 \%$ of patients received futile fractionated treatment. PS was a significant prognostic factor for survival. Based on these results, we suggest that PS should be one of the leading factors when choosing fractionated PTR. Patients with PS 0-1 should be considered for fractionated PTR whereas patients with PS $\geq 2$ should be considered for high-dose single fraction regime or supportive care alone.

\section{Additional files}

Additional file 1: Figure S1: Cox regression analysis showing correlation between OS and histology from prescription of PTR to death. Mixed AC/SCC is included. There was a significant difference in OS and histology, favoring both SCC and mixed AC/SCC over AC. Mixed AC/SCC had a HR $=0.25(95 \% \mathrm{Cl}: 0.12-0.51), p=0.000$. The rest of the results are listed in Fig. 1. (DOCX 26 kb)

Additional file 2: Figure S2. Cox regression analysis showing correlation between OS and age $>$ or $<70$ years from prescription of PTR to death. There was a trend towards better OS and high age, but this was not statistical significant. Age $>70$ years had a $\mathrm{HR}=0.79$ (95\% Cl: 0.58-1.09), $p=0.15$. (DOCX $25 \mathrm{~kb})$

Additional file 3: Figure S3. Cox regression analysis showing correlation between OS and radiotherapy schedules $25 \mathrm{~Gy} / 5 \mathrm{~F}$ or $30 \mathrm{~Gy} / 10 \mathrm{~F}$ from prescription of PTR to death. There was a trend towards better OS with 30Gy/10F but this was not statistical significant. 30Gy/10F had a $H R=0.74$ (95\% Cl: 0.52-1.04), $p=0.08$ (DOCX $25 \mathrm{~kb})$

\section{Abbreviations}

(AC): Adenocarcinoma; (ASCO): American society of clinical oncology; (ASTRO): The American society for radiation oncology; (EGFR): Epidermal growth factor receptor; (NSCLC): Non-small-cell lung cancer; (OS): Overall survival; (PFS): Progression free survival; (PS): Performance status; (PTR): Palliative thoracic radiotherapy; (QoL): Quality of life; (SCC): Squamous-cell carcinoma; (TNM): Tumor, node and metastasis classification of malignant tumors

\section{Acknowledgements}

Everyone involved in this article are listed as authors.

\section{Funding}

This study has not been funded.

\section{Availability of data and materials}

The dataset generated and analyzed during the current study is not publicly available due to that in the consent from Danish Data Protection Agency, an approval for publishing our database was not included. The data is available from the corresponding author on reasonable request.

\section{Authors' contributions}

GP, MSF and DSN all contributed equally to the conception and design of this study. MSF and DSN contributed equally with collecting data, writing and proofreading the manuscript. MSF wrote the draft for the manuscript and the following writing was done in collaboration. DSN has performed the statistical analyses in collaboration with LN. All 4 authors have discussed the interpretation of the results and have agreed on the scientific content and conclusion in the study. GP has critically supervised the process and all 4 authors have discussed and proofread the manuscript and given final approval for publication. All 4 authors are accountable for all aspects of the work. 


\section{Authors' information}

See front page.

\section{Ethics approval and consent to participate}

This study complies with national rules and regulations and is approved by the Danish Data Protection Agency. Journal number: 2012-58-0004. According to Danish law, no approval from Ethics Committee was necessary in this study.

\section{Consent for publication}

Not applicable

\section{Competing interests}

The authors declare that they have no competing interests.

\section{Publisher's Note}

Springer Nature remains neutral with regard to jurisdictional claims in published maps and institutional affiliations.

\section{Author details}

'Department of Oncology, Finsen Center, Rigshospitalet, Blegdamsvej 9, 2100 Copenhagen, Denmark. '2Section of Radiotherapy, Rigshospitalet, Blegdamsvej 9, 2100 Copenhagen, Denmark.

Received: 2 May 2017 Accepted: 28 December 2017

\section{Published online: 05 January 2018}

\section{References}

1. Collins LG, Haines C, Perkel R, et al. Lung cancer: diagnosis and management. Am Fam Physician. 2007;75:56-63.

2. Beckles MA, Spiro SG, Colice GL, et al. Initial evaluation of the patient with lung cancer: symptoms, signs, laboratory tests, and paraneoplastic syndromes. Chest. 2003;123:97S-104S

3. Wao H, Mhaskar R, Kumar A, et al. Survival of patients with non-small cell lung cancer without treatment: a systematic review and meta-analysis. Syst Rev. 2013;2:10

4. Langendijk JA, ten Velde GP, Aaronson NK, et al. Quality of life after palliative radiotherapy in non-small cell lung cancer: a prospective study. Int J Radiat Oncol Biol Phys. 2000;47:149-55.

5. Stevens $\mathrm{R}$, Macbeth $\mathrm{F}$, Toy $\mathrm{E}$, et al. Palliative radiotherapy regimens for patients with thoracic symptoms from non-small cell lung cancer. Cochrane Database Syst Rev. 2015;1:CD002143.

6. Rodrigues $G$, Videtic GM, Sur R, et al. Palliative thoracic radiotherapy in lung cancer: an American Society for Radiation Oncology evidence-based clinical practice guideline. Pract Radiat Oncol. 2011;1:60-71.

7. Kramer GW, Wanders SL, Noordijk EM, et al. Results of the Dutch national study of the palliative effect of irradiation using two different treatment schemes for non-small-cell lung cancer. J Clin Oncol. 2005;23:2962-70.

8. Gripp S, Moeller S, Bolke E, et al. Survival prediction in terminally ill cancer patients by clinical estimates, laboratory tests, and self-rated anxiety and depression. J Clin Oncol. 2007;25:3313-20.

9. Jacot W, Colinet B, Bertrand D, et al. Quality of life and comorbidity score as prognostic determinants in non-small-cell lung cancer patients. Ann Oncol. 2008;19:1458-64.

10. Rodrigues $G$, Macbeth F, Burmeister B, et al. International practice survey on palliative lung radiotherapy: third international consensus workshop on palliative radiotherapy and symptom control. Clin Lung Cancer. 2012;13:225-35.

11. Walasek T, Sas-Korczynska B, Dabrowski T, et al. Palliative thoracic radiotherapy for patients with advanced non-small cell lung cancer and poor performance status. Lung Cancer. 2015:87:130-5.

12. A Medical Research Council (MRC) randomised trial of palliative radiotherapy with two fractions or a single fraction in patients with inoperable non-small-cell lung cancer (NSCLC) and poor performance status. Medical Research Council Lung Cancer Working Party. Br J Cancer 1992; 65: 934-41.

13. Efficace F, Bottomley A, Smit EF, et al. Is a patient's self-reported health-related quality of life a prognostic factor for survival in non-small-cell lung cancer patients? A multivariate analysis of prognostic factors of EORTC study 08975. Ann Oncol. 2006:17:1698-704

14. Erridge SC, Gaze MN, Price A, et al. Symptom control and quality of life in people with lung cancer: a randomised trial of two palliative radiotherapy fractionation schedules. Clin Oncol (R Coll Radiol ). 2005;17:61-7.
15. Gripp S, Mjartan S, Boelke E, et al. Palliative radiotherapy tailored to life expectancy in end-stage cancer patients: reality or myth? Cancer. 2010;116:3251-6.

16. Maltoni M, Caraceni A, Brunelli C, et al. Prognostic factors in advanced cancer patients: evidence-based clinical recommendations-a study by the steering Committee of the European Association for palliative care. J Clin Oncol. 2005;23:6240-8.

17. Numico G, Russi E, Merlano M. Best supportive care in non-small cell lung cancer: is there a role for radiotherapy and chemotherapy? Lung Cancer. 2001;32:213-26.

18. Rees GJ, Devrell CE, Barley VL, et al. Palliative radiotherapy for lung cancer: two versus five fractions. Clin Oncol (R Coll Radiol ). 1997:9:90-5.

19. Schroder C, Ivo M, Buchali A. Does high-dose radiotherapy benefit palliative lung cancer patients?: an intradepartmental comparison of two dose regimens. Strahlenther Onkol. 2013;189:771-6.

20. Stanley KE. Prognostic factors for survival in patients with inoperable lung cancer. J Natl Cancer Inst. 1980;65:25-32.

21. Kapadia NS, Mamet R, Zornosa C, et al. Radiation therapy at the end of life in patients with incurable nonsmall cell lung cancer. Cancer. 2012;118:4339-45.

22. Koshy M, Malik R, Mahmood U, et al. Prevalence and predictors of inappropriate delivery of palliative thoracic radiotherapy for metastatic lung cancer. J Natl Cancer Inst. 2015;107:djv278.

23. Toole M, Lutz S, Johnstone PA. Radiation oncology quality: aggressiveness of cancer care near the end of life. J Am Coll Radiol. 2012;9:199-202.

24. van Oorschot B, Assenbrunner B, Schuler $M$, et al. Survival and prognostic factors after moderately hypofractionated palliative thoracic radiotherapy for non-small cell lung cancer. Strahlenther Onkol. 2014;190:270-5.

25. Macbeth FR, Bolger JJ, Hopwood P, et al. Randomized trial of palliative two-fraction versus more intensive 13-fraction radiotherapy for patients with inoperable non-small cell lung cancer and good performance status. Medical Research Council lung cancer working party. Clin Oncol (R Coll Radiol ). 1996;8: $167-75$

26. Plataniotis GA, Kouvaris JR, Dardoufas C, et al. A short radiotherapy course for locally advanced non-small cell lung cancer (NSCLC): effective palliation and patients' convenience. Lung Cancer. 2002;35:203-7.

27. Reinfuss M, Mucha-Malecka A, Walasek T, et al. Palliative thoracic radiotherapy in non-small cell lung cancer. An analysis of 1250 patients. Palliation of symptoms, tolerance and toxicity. Lung Cancer. 2011:71:344-9.

28. Senkus-Konefka E, Dziadziuszko R, Bednaruk-Mlynski E, et al. A prospective, randomised study to compare two palliative radiotherapy schedules for non-small-cell lung cancer (NSCLC). Br J Cancer. 2005;92:1038-45.

29. Simpson JR, Francis ME, Perez-Tamayo $R$, et al. Palliative radiotherapy for inoperable carcinoma of the lung: final report of a RTOG multi-institutional trial. Int J Radiat Oncol Biol Phys. 1985;11:751-8.

30. Sundstrom $S$, Bremnes RM, Brunsvig $P$, et al. Palliative thoracic radiotherapy in locally advanced non-small cell lung cancer: can quality-of-life assessments help in selection of patients for short- or long-course radiotherapy? J Thorac Oncol. 2006;1:816-24.

31. Nieder C, Tollali T, Haukland E, et al. External validation of a prognostic score for patients receiving palliative thoracic radiotherapy for lung cancer. Clin Lung Cancer. 2017:18(4):e297-301.

32. Rades D, Kasmann L, Schild SE, et al. A survival score for patients receiving palliative irradiation for locally advanced lung cancer. Clin Lung Cancer. 2016;17:558-62.

33. Turner NJ, Muers MF, Haward RA, et al. Do elderly people with lung cancer benefit from palliative radiotherapy? Lung Cancer. 2005:49:193-202.

34. Falk SJ, Girling DJ, White RJ, et al. Immediate versus delayed palliative thoracic radiotherapy in patients with unresectable locally advanced non-small cell lung cancer and minimal thoracic symptoms: randomised controlled trial. BMJ. 2002:325:465.

35. Sundstrom S, Bremnes R, Brunsvig P, et al. Immediate or delayed radiotherapy in advanced non-small cell lung cancer (NSCLC)? Data from a prospective randomised study. Radiother Oncol. 2005;75:141-8.

36. Neuss MN, Desch CE, McNiff KK, et al. A process for measuring the quality of cancer care: the quality oncology practice initiative. J Clin Oncol. 2005;23: 6233-9.

37. Patel A, Dunmore-Griffith J, Lutz S, et al. Radiation therapy in the last month of life. Rep Pract Oncol Radiother. 2014;19:191-4

38. Jassem J. The role of radiotherapy in lung cancer: where is the evidence? Radiother Oncol. 2007;83:203-13. 